\title{
Energy efficiency of improvement of agriculture optimization technology and machine complex optimization
}

\author{
A $K$ Apazhev, $A$ G Fiapshev, Iu A Shekikhachev*, $L M$ Khazhmetov, $A$ L Khazhmetova and $K h$ Kh Ashabokov \\ FSBEI HE “Kabardino-Balkarian State Agrarian University named after V M Kokov”, Nalchik, Russia
}

\begin{abstract}
To ensure the food security of the Russian Federation, one of the priority areas of the state's economic and food policy is a step-by-step reduction of the dependence of the domestic agroindustry complex on the import of technologies, machines, and equipment. Currently, machines and aggregates that perform one specific operation are often used in preparing the soil for sowing crops; their multiple passes along the surface of the field being treated increase energy costs, lead to soil compaction, emergence and development of erosion processes. Considering this, further improvement of cultivation technologies, machines and units for soil preparation and sowing crops is required. To solve this problem, we propose an improved technology and an optimized complex of machines that can perform plowing, crushing soil blocks, mulching the topsoil, and sowing. The use of the proposed technology and an optimized machinery complex for the cultivation of winter wheat in the Central part of the North Caucasus resulted in a decrease in: direct energy costs by $33.5 \%$; living labor costs by $31.7 \%$; specific energy consumption of MTA by $41.7 \%$; materialized energy costs by $50 \%$; energy consumption for sowing by $7.7 \%$. As a result, total energy costs decreased by $34 \%$.
\end{abstract}

\section{Introduction}

Nowadays, the fuel and energy problem is especially acute, due to the limited proven reserves of fuel. The problem of energy supply in the agroindustry complex is complicated by the need to increase food production, caused by the growth of the total population and its wellbeing, as well as a noticeable decrease in the number of rural residents. Agriculture has become a major energy consumer, especially of petroleum products, to be more exact, it is responsible for $15 \%$ of all energy costs and $40 \%$ of expense of oil products [1-3].

Thus, the dominant criterion for the efficiency of agricultural production and the rational use of the resources involved is a decrease in energy consumption.

For the preference of any element from the compared, an energy audit is conducted. In this case, we assume that each indicator is represented in the form of its energy content, which is determined by multiplying energy costs associated with its production by the corresponding energy equivalent or the coefficient. The advantage of energy assessment in comparison with financial assessment is its fairness, since there is no influence of the economic situation in the country or of a specific pricing and branding policy of the brand. Also, energy analysis allows us to determine the energy efficiency of the estimated unit or complex of machines.

The main objective of optimization is to establish a combination of technical means that allows acquiring products with the best performance. Thus, it becomes possible to identify the optimal combination of technical means for a particular technological process.

The assessment is made in accordance with the criterion of total energy costs.

It was established that the technological processes of pre-sowing soil preparation and winter wheat sowing in the conditions of the Central part of the North Caucasus are characterized by significant energy costs. Therefore, there is an urgent need to improve technology and optimize the complex of machines for pre-sowing soil preparation and sowing of winter wheat with minimal energy costs.

The technologies used in the farms of the region involve: two to four peeling, fertilizing, plowing, harrowing, two to four cultivations, pre-sowing rolling, sowing.

The proposed solution involves the implementation of technological operations on the application of bioorganic fertilizer, pre-sowing preparation of the soil with the developed combined tillage unit, leveling and compaction of the seed layer with the developed combined tillage train, sowing with the use of an advanced grain seeder.

Using the proposed machinery complex should result in an increase in the quality of pre-sowing preparation of soil and sowing, as well as a reduction in energy costs.

It is possible to reduce energy costs for the implementation of technological processes by optimizing the parameters of the machines used. In addition, it is possible to reduce or combine technological methods. The proposed option involves the complete preparation

*Corresponding author: shek-fmep@mail.ru 
of soil for sowing when using a combined tillage unit and a combined tillage train.

\section{Materials and methods}

The studies were carried out using system analysis, mathematical modeling and structural analysis of technological processes based on the laws of classical mechanics, mathematical statistics, and the theory of planning a multivariate experiment. The studies were conducted in accordance with the requirements of interstate standards and proprietary methods.

The proposed technology for pre-sowing soil preparation and sowing of grain crops is based on the following:

- using a bioorganic fertilizer produced by the developed bioreactor;

- plowing with simultaneous grinding of soil blocks using the developed combined tillage unit;

- leveling and compaction of the seed layer using the developed combined tillage train;

- sowing with an advanced grain seeder.

The experiments to determine the yield of winter wheat of the Yuka variety were carried out on a plot 300 $\mathrm{m}$ wide and $1000 \mathrm{~m}$ long.

We were comparing the work of a serial SZP-3.6 seeder and an improved SZP-3.6 seeder. The soil was prepared for sowing as follows:

- when sowing with a serial grain seeder SZP-3.6 according to traditional technology using serial technical means;

- when sowing with an improved grain seeder according to an improved technology using developed technical means.

Sowing was done using shuttle method, the speed of sowing units was 2.5 to $2.6 \mathrm{~m} / \mathrm{s}$.

Processing of experimental results was performed using the Microsoft Excel 2010 software product.

The mathematical model that analytically describes the reduction in total energy costs has the form [4-8]:

$$
\sum_{i=1}^{n} \sum_{j=1}^{n} E_{\sum i j} \rightarrow \min
$$

Total energy savings (the difference between the energy costs for the base and proposed options) should be maximum:

$$
\Delta E_{\Sigma}=E_{\Sigma \mathrm{B}}-E_{\Sigma \mathrm{P}} \rightarrow \max .
$$

The expression for the efficiency coefficient is as follows:

$$
C_{E}=\frac{E_{\Sigma \mathrm{P}}}{E_{\Sigma \mathrm{B}}} \prec 1 .
$$

Considering (3), the intensification level can be calculated using the following expression:

$$
I_{E}=\left(1-C_{E}\right) 100
$$

The total energy costs are the sum of the energy costs: direct $E_{D}$, living labor $E_{L L}$, specific energy $E_{M T A}$, materialized $E_{M}$, due to the reduction of agrotechnological indicators $E_{A}$ :

$$
E_{\Sigma}=E_{D}+E_{L L}+E_{M T A}+E_{M}+E_{A}
$$

The direct energy costs can be calculated using the expression:

$$
E_{D_{i j}}=H_{T_{i j}}\left(a_{T}+f_{T}\right)
$$

where $H_{T_{i j}}$ is fuel and lubricants consumption of $i$-th tractor on $j$-th iteration, $\mathrm{kg} / \mathrm{ha} ; a_{T}$ is energy capacity of fuels and lubricants, $\mathrm{MJ} / \mathrm{kg} ; f_{T}$ is a coefficient characterizing the energy consumption in the production of fuels and lubricants.

$E_{L L}$ is calculated using the following expression:

$$
E_{L L_{i j}}=\frac{\left(n_{M L_{i j}} a_{L L(M)}+n_{T L_{i j}} a_{L L(T)}\right)}{W_{S_{i j}}},
$$

where $n_{M L_{i j}}$ is number of the main staff of $i$-th MTA on $j$-th iteration, units; $a_{L L(M)}$ is an energy equivalent of the labor of the main staff, MJ/unit; $n_{T L_{i j}}$ is number of temporary staff of $i$-th MTA on $j$-th iteration, units; $a_{L L(T)}$ is an energy equivalent of the labor of the temporary staff, MJ/unit; $W_{S_{i j}}$ is shift performance of $i$ th machine on $j$-th iteration, ha.

$E_{M T A}$ was calculated using the following expression:

$$
E_{M T A_{i j}}=\frac{E_{E T_{i j}}+E_{A M_{i j}}}{W_{S_{i j}}},
$$

where $E_{E T_{i j}}$ is specific energy consumption of the $i$-th energy tool on $j$-th iteration, $\mathrm{MJ} / \mathrm{ha} ; E_{A M_{i j}}$ is specific energy consumption of $i$-th agricultural machine on $j$-th iteration, $\mathrm{MJ} / \mathrm{ha}$.

$E_{E T i j}$ is calculated according to the expression:

$$
E_{E T i j}=\frac{M_{E T_{i j}} a_{E T_{i j}}\left(K_{E T(R)_{i j}}+K_{E T(O)_{i j}}+K_{E T(M)_{i j}}\right)}{100 T_{E T(L)_{i j}}},
$$

where $M_{E T_{i j}}$ is mass of $i$-th energy tool on $j$-th iteration, $\mathrm{kg}$; $a_{E T_{i j}}$ is energy equivalent of $i$-th energy tool on $j$-th iteration, $\mathrm{MJ} / \mathrm{kg} ; K_{E T(R)_{i j}}, K_{E T(O)_{i j}}, K_{E T(M)_{i j}}$ are standards for deductions for renovation, overhaul and maintenance of $i$-th energy tool on $j$-th iteration, $\%$; $T_{E T(N)_{i j}}$ is regulatory load of $i$-th energy tool on $j$-th iteration, $\mathrm{h}$.

$E_{A M_{i j}}$ is calculated according to the expression:

$$
E_{A M_{i j}}=\frac{M_{A M_{i j}} a_{A M_{i j}}\left(K_{A M(R)_{i j}}+K_{A M(M)_{i j}}\right)}{100 T_{A M(L)_{i j}}},
$$


Table 1. Energy efficiency calculation results, MJ / ha.

\begin{tabular}{|l|c|c|c|c|}
\hline \multirow{2}{*}{ Name } & \multicolumn{2}{|c|}{ Case } & Difference & \% \\
\cline { 2 - 5 } & basic & proposed & & \\
\hline Direct energy costs & 1872.7 & 1244.7 & 628 & 33.5 \\
\hline Living labor costs & 3.81 & 2.6 & 1.21 & 31.7 \\
\hline $\begin{array}{l}\text { The specific energy consumption of the machine- } \\
\text { tractor unit }\end{array}$ & 422.93 & 246.55 & 176.38 & 41.7 \\
\hline Materialized energy costs & 5600 & 2800 & 2800 & 50.0 \\
\hline Sowing energy costs & 3473.6 & 3206.4 & 267.2 & 7.7 \\
\hline Total energy costs & 11373.04 & 7500.25 & 3872.79 & 34.0 \\
\hline
\end{tabular}

where $M_{A M_{i j}}$ is mass of $i$-th agricultural machine on $j$-th iteration, $\mathrm{kg} ; a_{A M_{i j}}$ is energy equivalent of $i$-th agricultural machine on $j$-th iteration, $\mathrm{MJ} / \mathrm{kg}$; $K_{A M(R)_{i j}}, K_{A M(M)_{i j}}$ are expenses for renovation amd maintenance of $i$-th agricultural machine on $j$-th interval, $\% ; T_{A M(L) i j}$ is regulatory load of $i$-th agricultural machine on $j$-th iteration, $\mathrm{h}$.

$E_{M}$ is calculated using the following expression:

$$
E_{M}=\frac{a_{M} R_{M}}{T_{M}},
$$

where $a_{M}$ is energy equivalent, $\mathrm{MJ} / \mathrm{kg}$ or $\mathrm{MJ} / \mathrm{t} ; R_{M}$ is spread rate, $\mathrm{kg} / \mathrm{ha}$ or $\mathrm{g} / \mathrm{ha} ; T_{M}$ is time, during which the substance is active, years.

The expenses $E_{A}$ are determined by unevenness of seed distribution $\left(E_{U D}\right)$, dosing accuracy $\left(E_{D A}\right)$, seed trauma rate $\left(E_{T R}\right)$ :

$$
E_{A}=E_{U D}+E_{D A}+E_{T R} .
$$

$E_{U D}$ can be evaluated using the amount of energy in the crops that has not been obtained in the base case.

$E_{D A}$ is calculated taking into account the seeding rates of the basic $\left(Q_{B}\right)$ and new proposed $\left(Q_{P}\right)$ cases, and the energy contents $\left(E_{U}\right)$ using the following expression:

$$
E_{D A}=\left(Q_{B}-Q_{P}\right) E_{U}
$$

$E_{T R}$ is calculating using the seed trauma rate coefficient $K_{T R}$ :

$$
E_{T R}=\left(Q_{B}-Q_{P}\right) E_{U} K_{T R}
$$

Possible options for presowing soil preparation and winter wheat sowing [9-15]:

- basic: application of solid organic fertilizers (ROU6A), plowing (PLN-3-35), cultivation (KPS-4), presowing cultivation (KPS-4), pre-sowing rolling (3KKSH-6), sowing (SZP-3.6);

- proposed: application of solid bioorganic fertilizers (ROU-6A), plowing with simultaneous grinding of soil blocks (KPA), leveling and compaction of the seed layer (KPSh), sowing (advanced grain seeder SZP-3.6).

\section{Results and discussion}

The results of calculations of establishing the structure of energy costs and energy efficiency indicators for presowing soil preparation and winter wheat sowing [9-15]

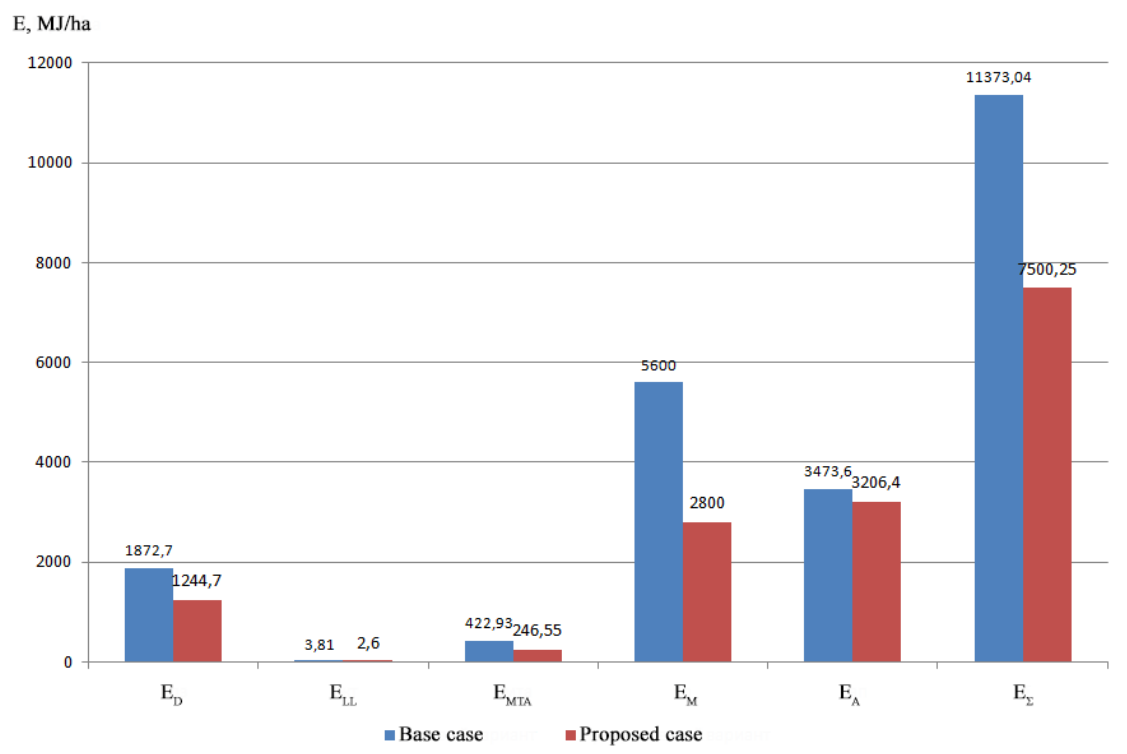

Fig. 1. Energy costs for pre-sowing soil preparation and winter wheat sowing. 
are shown in the following table 1 and figure 1.

The results obtained indicate that when using the proposed option in comparison with the base one, the following are reduced: direct energy costs by $33.5 \%$; living labor costs by $31.7 \%$; specific energy consumption of MTA by $41.7 \%$; materialized energy costs by $50 \%$; energy consumption for sowing by $7.7 \%$. We need to note a decrease in total energy costs by $34 \%$

The calculation has demonstrated that $C_{E}=0,66 \prec$ $1, I_{E}=34 \%$.

The additional energy output as a result of comparing the yield with the basic $U_{B}$ and proposed $U_{P}$ cases is determined according to the expression:

$$
E_{A D D}=\left(U_{P}-U_{B}\right) E_{U} \text {. }
$$

Taking into account the fact that the yield in the proposed option, compared with the base one, increased on average by $0.53 \mathrm{t} / \mathrm{ha}$, we obtain $E_{A D D}=7080.8 \mathrm{MJ} / \mathrm{ha}$. Additional profit in cash equivalent will amount to 3961 rubles/ha.

\section{Conclusions}

Improved technology and an optimized complex of machines for pre-sowing soil preparation and winter wheat sowing in the conditions of the Central part of the North Caucasus have reduced: direct energy costs by $33.5 \%$; living labor costs by $31.7 \%$; specific energy consumption of MTA by $41.7 \%$; materialized energy costs by $50 \%$; energy consumption for sowing by $7.7 \%$. Total energy costs decreased by $34 \%$. The efficiency coefficient was 0.66 , the level of intensification was $34 \%$.

An additional energy output due to an increase in productivity by an average of $0.53 \mathrm{t} / \mathrm{ha}$ was $7080.8 \mathrm{MJ} / \mathrm{ha}$.

\section{References}

1. Methodology of energy analysis of technological processes in agricultural production, 96 (1995)

2. Methodology of fuel and energy assessment of crop production, 84 (2012)

3. Methods and methodology of energy assessment of agricultural technologies in agricultural landscapes, 21 (2007)

4. Methodology for determining the economic efficiency of technology and agricultural machinery. Normative and reference material, 1, 217 (1998)

5. Methodology for determining the economic efficiency of technologies and agricultural machinery. Normative and reference material, 251 (1998)

6. V.G. Sychev, M.A. Aliev, Methodology of energy assessment of agricultural cultivation technologies, Collection of All-Russian Works, 1, 139-44 (2010)

7. A.P. Kormanovsky, Energy conservation as the first priority in the coming century, Engineering in agriculture, 4, 3-6 (1999)
8. S.N. Salenkov, Modern energy-saving technologies in crop production, Newsletter of the Ministry of Agriculture of the Russian Federation, 7, 28-32 (2001)

9. E.V. Kyul, A.K. Apazhev, A.B. Kudzaev, N.A. Borisova, Influence of anthropogenic activity on transformation of landscapes by natural hazards Indian, Journal of Ecology, 44(2), 239-43 (2017)

10. A.K. Apazhev, Yu. A. Shekikhachev, L.M. Khazhmetov, The results of production tests of a combined tillage unit, Rural machine, 8, 10-11 (2016)

11. A.K. Apazhev, M.M. Kosheev, Combined tillage machines for pre-sowing soil preparation, Innovations in the agricultural complex, 10-12 (2017)

12. A.K. Apazhev, Z.Sh. Appaev, Ways to reduce the traction resistance of a plow plow, Ural Agrarian Bulletin, 3, 24-5 (2012)

13. A.K. Apazhev, Yu. A. Shekikhachev, L.M. Khazhmetov, Rational parameters and operating modes of the combined tillage unit, News of Gorsky State Agrarian Universit, 53(2), 138-43 (2016)

14. A.K. Apazhev, Yu. A. Shekikhachev, A.G. Fiapshev, Development and research of a bioreactor for biofertilizer and biogas, Bulletin of Kazan State Agrarian University, 2(40), 60-3 (2016)

15. A.K. Apazhev, Yu. A. Shekikhachev, L.M. Khazhmetov, Modernization of a grain seeder for work in conditions of high soil moisture, News of Nizhnevolzhsky agro-university complex: Science and higher professional education, 3(43), 238-45 (2016) 